\title{
Factors Affecting the Durability of Silk Plankton Tow-nets and Young Fish Trawl-nets.
}

\author{
By \\ W. R. G. Atkins, O.B.E., Sc.D., F.I.C., \\ Head of the Department of General Physiology at the Plymouth Laboratory.
}

OwING to the combined action of bacteria, sunlight, sea-water, and general wear and tear the costly silk tow-nets when in constant use are only found to last a few months, or with less use for over twelve months. The young fish trawl-nets, made of a hemp material known as "stramin," if used several times a week are expected to last over three months.

It is the general impression that silk nets should be washed in freshwater and dried after every time they are used.

It was suggested by Dr. G. Barr, of the National Physical Laboratory, that an antiseptic bath might prolong the life of such nets through lessening bacterial action. One is, however, limited in a choice of preservatives by the fact that it is necessary to avoid anything that may clog the fine meshes, cause shrinkage, or be likely to damage the fibre. Since formalin is in constant use for preserving plankton hauls it appeared worth while trying it on the nets also. It is, however, known that acids injuriously affect fabrics, and commercial formalin is as acid as $\mathrm{pH} 2.8$ when purchased, and produces acid on standing, in sunlight especially. The formalin was accordingly rendered slightly more alkaline than seawater by the addition of a little borax, which remains as a buffer to neutralise acidity when generated.

Exposure tests were made with the various fabrics stretched loosely on frames upon the Laboratory roof and subjected to treatment as detailed below.

\section{Young Fish Trawl-net.}

1. Dry control, stored in dark.

2. Frame exposed to weather on roof, March 14 to April 27, 43 days.

3. Soaked daily for 10 minutes in sea-water for 35 out of 43 days, exposed on roof as No. 2.

4. As No. 3, save that once a week, six times in all, the sea-water treatment was followed by 10 minutes in $5 \%$ formalin brought to $\mathrm{pH} 8 \cdot 5-9 \cdot 0$ with borax. 
Tensile tests were carried out at the National Physical Laboratory, as set forth in the report which is appended, but taking the figures. for the control as one hundred the various treatments resulted in deterioration, as shown by the following table :-

Young Fish Trawl,

$\begin{array}{ccccc} & \text { 1. Controi. } & \text { 2. Exposure. } & \text { 3. } \begin{array}{c}\text { Exposure } \\ \text { Sea-water. }\end{array} & \begin{array}{c}\text { 4. As } 3+ \\ \text { Formalin. }\end{array} \\ \text { Weft } & 100 & 94 & 93 & 83 \\ \text { Warp } & 100 & 83 & 88 & 75\end{array}$

It is at once obvious that the occasional treatment with formalin is injurious, and that sea-water has no more effect than the rain received by Nos. 2 and 3 alike. Within the six weeks, however, the general weathering has been considerable, and might be more noticeable with the intenser light of summer and during the longer days. Since, however, the net is expected to last only for about three months it seems that mechanical injuries must add largely to its rate of deterioration.

Tow -NET, silk, double anchor, lion and cable brand, 25 mesh per inch.

1. Dry control; stored in dark.

2. Frame exposed on roof, 43 days.

3. Ten minutes sea-water.

Ten minutes fresh-water.

Dried on roof (if fine), total exposure 14 hours.

Treated as above, 35 out of 43 days.

Stored in dark.

4. As No. 3, but treated for 10 minutes daily with $5 \%$ neutralised formalin after sea-water and before fresh-water washing.

The percentage results of the tensile tests are shown as before.

Tow-NET, 25 mesh.

1. Control.

$\begin{array}{ll}\text { Weft } & 100 \\ \text { Warp } & 100\end{array}$

2. Exposure.

57

53
3. Sea-water, fresh-water.

89

89
4. As 3, with formalin. 86

86

It is clear that exposure to light results in rapid deterioration of the silk, whereas the sea- and fresh-water treatments have had far less effect. Formalin treatment is again shown to be distinctly injurious. 
Tow-NET, silk, 100 mesh per inch, same brand.

1. Dry control, stored in dark.

2. Kept in $5 \%$ borax formalin.

3. Ten minutes daily in sea-water, 35 days out of 43 ; kept on roof 43 days.

4. As No. 3, but treated with fresh-water for ten minutes daily after sea-water.

The percentage results are as follows :-

Tow-NET, silk, 100 mesh.

$\begin{array}{lcccc} & \text { 1. Control. } & \begin{array}{c}\text { 2. In 5\% } \\ \text { Formalin. }\end{array} & \begin{array}{c}\text { 3. Exposed, } \\ \text { sea-water. }\end{array} & \begin{array}{c}\text { 4. As 3, but } \\ \text { rinsed. }\end{array} \\ \text { Weft } & 100 & 90 & 50 & 47 \\ \text { Warp } & 100 & 94 & 46 & 45\end{array}$

The foregoing figures show that formalin, even in the dark, has a deleterious influence on silk. Furthermore, the damage to the 100-mesh silk due to exposure results in a loss of over half its strength in six weeks, even in spring. Instead of improving matters the extra washing in freshwater has resulted in an additional weakening.

\section{SUMMARY AND RECOMMENDATIONS.}

1. Sunlight is the main cause of weakening of nets and tow-nets when exposed but not in use, and is more important than bacterial action. As weakening progresses mechanical injuries are likely to assume an important place as damaging agents.

2. Formalin, tried as a preservative, has been found to be injurious.

3. Rinsing in fresh-water, after using silk nets in salt-water, has been proved to damage the nets when carried out daily. The practice is accordingly not recommended; nevertheless it seems advisable to rinse out a net in fresh-water before prolonged storing, as it remains drier.

4. As far as possible all nets should be kept from sunlight, once they have been dried. They should then be stored without further treatment. The deterioration of silk nets is specially rapid when exposed to sunlight. When possible dry in the shade in a breeze.

Details of the tests made by Dr. Barr are contained in a report from the Director of the National Physical Laboratory which runs as follows :-

The samples consisted of pieces about 18 inches square of three fabrics marked YFT, 1-4, tow-net 25, 1-4 and tow-net 100, 1-4, which had 
been variously treated. Owing to shrinkage, some of the squares were distorted ; in the tensile tests the slope of the cross threads was neglected and the threads under test merely stretched as evenly as possible between the grips.

The changes in weight per square metre were found to vary in much the same sense as the changes in dimensions: consequently the ends and picks were counted accurately and no exact determinations of weight were made, since these would not enable any deductions to be made as to gain or loss of substance from the fabrics.

For the tensile tests six test pieces were cut in each direction from each sample of dimensions such as to allow them to be frayed down to about 2 inches in width, leaving 7 inches between grips. (Four of the test pieces from tow-net 100, 4 had to be taken 1 inch shorter.) In view of the above-mentioned contraction, the width to which the pieces were frayed was not a constant but was such as to include the same number of threads in corresponding test pieces: the table gives the breaking load for a piece containing the stated number of threads.

The number of threads per inch was counted in nine places in each direction for each sample. The numbers given in the table below stand in positions which are related to the position of the count in the square of fabric.

Young Fish-Trawl.-Rate of loading $200 \mathrm{lb}$. per minute.

Breaking loads of weft pieces containing 40 picks.

Y.F.T. 1 Weft. Y.F.T. 2 Weft. Y.F.T. 3 Weft.

$\begin{array}{cccc}\text { T. 1 Weft. } & \text { Y.F.T. 2 Weft. } & \text { Y.F.T. 3 Weft. } & \text { Y.F.T. } 4 \text { Weft. } \\ \text { lbs. } & \text { lbs. } & 221 \cdot 0 & 199 \cdot 0 \\ 244 \cdot 0 & 227 \cdot 0 & 221 \cdot 0 & 211 \cdot 0 \\ 244 \cdot 0 & 222 \cdot 0 & 223 \cdot 5 & 161 \cdot 0 \\ 243 \cdot 0 & 216 \cdot 5 & 226 \cdot 0 & 190 \cdot 0 \\ 239 \cdot 0 & 223 \cdot 0 & 255 \cdot 0 & 202 \cdot 0 \\ 237 \cdot 0 & 222 \cdot 0 & 183 \cdot 0 & 221 \cdot 5 \\ 224 \cdot 0 & 229 \cdot 0 & & \end{array}$

$\begin{array}{llll}\text { Mean : } \quad 238 \cdot 5 & 223 \cdot 2 & 221 \cdot 6 & 197 \cdot 4\end{array}$

Breaking loads of warp pieces containing 30 ends.

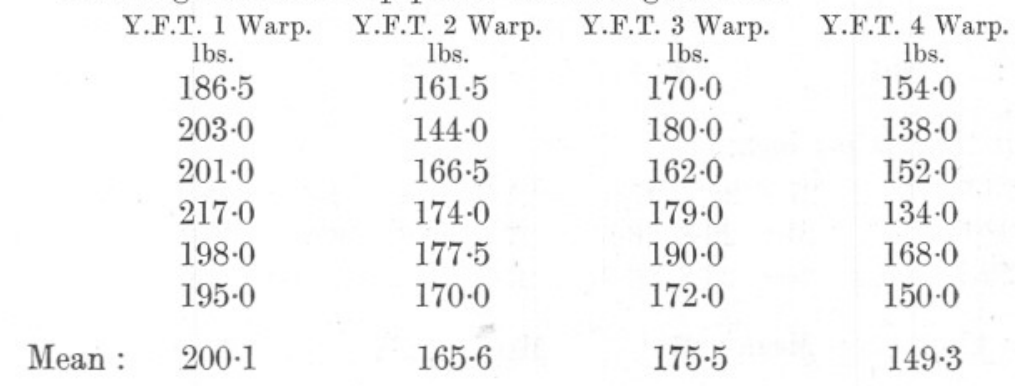


Weft threads per inch.

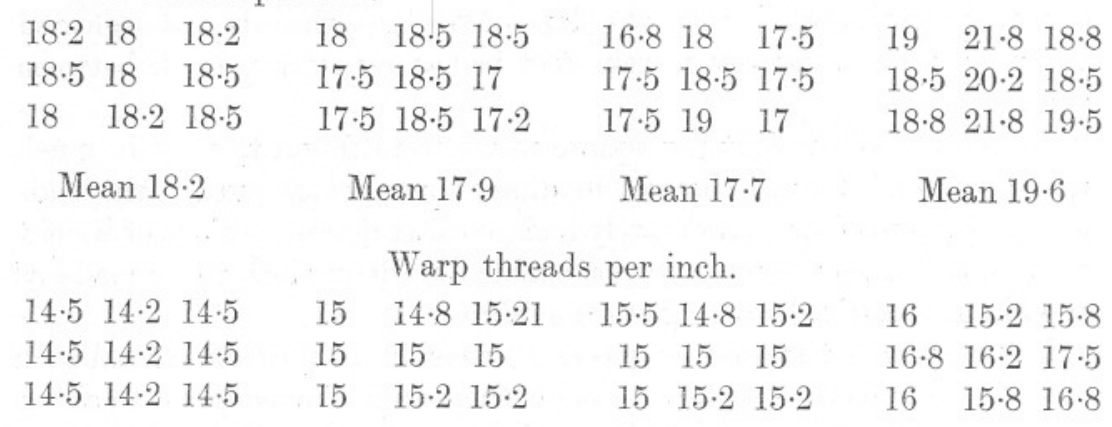

Mean : $14 \cdot 4$ Mean : $15 \cdot 0 \quad$ Mean : $15 \cdot 1 \quad$ Mean : $16 \cdot 2$

Tow-Net, 25 Mesh.- Rate of loading $100 \mathrm{lb}$. per minute.

Breaking loads of weft pieces containing 50 picks.

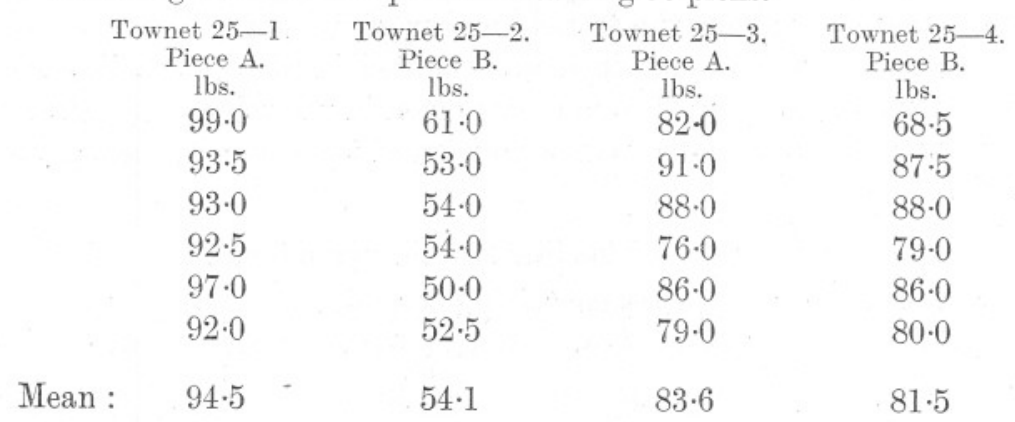

Breaking loads of warp pieces containing 50 ends.

\begin{tabular}{|c|c|c|c|c|c|c|c|c|}
\hline & \multicolumn{2}{|l|}{$\begin{array}{l}\text { Warp. } \\
90 \cdot 0\end{array}$} & \multicolumn{2}{|c|}{$\begin{array}{c}\text { Warp. } \\
46 \cdot 0\end{array}$} & \multicolumn{3}{|c|}{$\begin{array}{l}\text { Warp. } \\
83.5\end{array}$} & $\begin{array}{l}\text { Warp. } \\
74 \cdot 5\end{array}$ \\
\hline & \multicolumn{2}{|l|}{$91 \cdot 0$} & \multicolumn{2}{|c|}{$50 \cdot 0$} & \multicolumn{3}{|c|}{$78 \cdot 5$} & $80 \cdot 0$ \\
\hline & \multicolumn{2}{|l|}{$88 \cdot 5$} & \multicolumn{2}{|c|}{$52 \cdot 0$} & \multicolumn{3}{|c|}{$76 \cdot 0$} & $75 \cdot 0$ \\
\hline & \multicolumn{2}{|l|}{$90 \cdot 0$} & \multicolumn{2}{|c|}{$46 \cdot 0$} & \multicolumn{3}{|c|}{$82 \cdot 0$} & $79 \cdot 5$ \\
\hline & \multicolumn{2}{|l|}{$92 \cdot 0$} & \multicolumn{2}{|c|}{$50 \cdot 0$} & \multicolumn{3}{|c|}{$80 \cdot 0$} & $80 \cdot 0$ \\
\hline & \multicolumn{2}{|l|}{$93 \cdot 0$} & \multicolumn{2}{|c|}{$48 \cdot 0$} & \multicolumn{3}{|c|}{$85 \cdot 0$} & $79 \cdot 0$ \\
\hline Mean : & \multicolumn{2}{|l|}{$90 \cdot 7$} & \multicolumn{2}{|c|}{$48 \cdot 6$} & \multicolumn{3}{|c|}{$80 \cdot 8$} & $78 \cdot 0$ \\
\hline \multicolumn{9}{|c|}{ Weft threads per inch. } \\
\hline $25 \cdot 5 \quad 25 \cdot 5$ & 26 & 27 & 28 & $27 \cdot 5$ & $27 \cdot 5$ & $27 \cdot 8$ & $27 \cdot 5$ & $27.5 \quad 27 \cdot 5 \quad 28$ \\
\hline $26.5 \quad 26 \cdot 5$ & $26 \cdot 5$ & 27 & $26 \cdot 8$ & $26 \cdot 5$ & 27 & $26 \cdot 8$ & $26 \cdot 5$ & $27.5 \quad 28.5 \quad 28$ \\
\hline $25 \quad 25 \cdot 5$ & $25 \cdot 5$ & $26 \cdot 8$ & $26 \cdot 8$ & $26 \cdot 8$ & $27 \cdot 5$ & $27 \cdot 5$ & 27 & $27 \cdot 5 \quad 28 \quad 28$ \\
\hline Mean : 25 & & Mear & $n: 27$ & & Mean & $: 27 \cdot 2$ & & Mean : $27 \cdot 8$ \\
\hline
\end{tabular}


Warp threads per inch.

$\begin{array}{llllllllllll}25 \cdot 5 & 25 & 25 & 26 & 25 \cdot 2 & 25 \cdot 2 & 25 \cdot 8 & 25 \cdot 2 & 25 \cdot 5 & 26 & 25 \cdot 5 & 25 \cdot 5 \\ 25 \cdot 5 & 25 & 25 & 26 & 25 \cdot 5 & 25 \cdot 2 & 25 \cdot 8 & 26 \cdot 5 & 25 \cdot 5 & 26 & 25 \cdot 5 & 25 \cdot 8 \\ 25 \cdot 5 & 25 & 25 & 26 & 25 \cdot 5 & 25 \cdot 2 & 26 & 25 \cdot 8 & 25 \cdot 5 & 26 & 26 & 25 \cdot 8 \\ \text { Mean : } 25 \cdot 2 & \text { Mean : } 25 \cdot 5 & \text { Mean : } 25 \cdot 7 & & \text { Mean : } 25 \cdot 8\end{array}$

Tow-Net, 100 Mesh.-Rate of loading $80 \mathrm{lb}$. per minute.

Breaking loads of weft pieces containing 200 picks.

$\begin{array}{cccc}\begin{array}{c}\text { Tow-net 100-1. } \\ \text { Piece B. }\end{array} & \begin{array}{c}\text { Tow-net } 100-2 . \\ \text { Piece A. }\end{array} & \begin{array}{c}\text { Tow-net } 100-3 . \\ \text { Piece A. }\end{array} & \begin{array}{c}\text { Tow-net } 100-4 . \\ \text { Piece B. }\end{array} \\ 67 \cdot 5 & \text { lbs. } & \text { lbs. } & \text { lbs. } \\ 62 \cdot 0 & 65 \cdot 5 & 29 \cdot 0 & 23 \cdot 0 \\ 69 \cdot 0 & 60 \cdot 0 & 37 \cdot 0 & 30 \cdot 0 \\ 66 \cdot 5 & 62 \cdot 5 & 33 \cdot 5 & 30 \cdot 5 \\ 72 \cdot 0 & 65 \cdot 0 & 28 \cdot 0 & 33 \cdot 0 \\ 70 \cdot 0 & 68 \cdot 5 & 36 \cdot 0 & 38 \cdot 0 \\ 67 \cdot 8 & 42 \cdot 5 & 38 \cdot 0 & 36 \cdot 5 \\ : & 60 \cdot 6 & 33 \cdot 6 & 31 \cdot 8\end{array}$

Breaking loads of warp pieces containing 200 ends.

$\begin{array}{rlll}68 \cdot 0 & 63 \cdot 0 & 29 \cdot 5 & 25 \cdot 0 \\ 71 \cdot 0 & 66 \cdot 0 & 34 \cdot 0 & 30 \cdot 5 \\ 69 \cdot 5 & 65 \cdot 5 & 16 \cdot 0 & 32 \cdot 0 \\ 69 \cdot 5 & 60 \cdot 0 & 35 \cdot 0 & 34 \cdot 0 \\ 69 \cdot 5 & 64 \cdot 0 & 33 \cdot 0 & 31 \cdot 0 \\ 61 \cdot 0 & 66 \cdot 0 & 39 \cdot 0 & 30 \cdot 0 \\ \text { Mean : } 68 \cdot 1 & 64 \cdot 1 & 31 \cdot 1 & 30 \cdot 4\end{array}$

Weft threads per inch:

\begin{tabular}{rrllllllllll}
99 & 100 & 100 & 110 & 109 & 110 & 110 & 119 & 110 & 115 & 116 & 111 \\
95 & 95 & 96 & 110 & 108 & 109 & 104 & 119 & 107 & 107 & 112 & 104 \\
99 & 100 & 96 & 111 & 110 & 111 & 114 & 119 & 109 & 113 & 119 & 115 \\
\multicolumn{1}{c}{ Mean : 98} & \multicolumn{3}{c}{ Mean : 110} & & Mean : 112 & & Mean : 112
\end{tabular}

Warp threads per inch.

\begin{tabular}{llllllllllll}
96 & 98 & 99 & 112 & 107 & 105 & 106 & 103 & 103 & 102 & 100 & 100 \\
96 & 97 & 102 & 111 & 107 & 105 & 109 & 99 & 101 & 103 & 100 & 102 \\
95 & 98 & 100 & 109 & 107 & 105 & 102 & 99 & 99 & 101 & 98 & 98 \\
\multicolumn{1}{l}{ Mean : 98 } & \multicolumn{1}{c}{ Mean : 108 } & &
\end{tabular}

(Signed) J. E. Petavel, Director.

Per G. Barr. 